\title{
Some Tests of Avalanche Photodiodes Produced by Advanced Photonix, Inc.
}

\author{
G.W. Foster and A. Ronzhin \\ Fermi National Accelerator Laboratory \\ P.O. Box 500, Batavia, Illinois 60510
}

Roger Rusack

University of Minnesota

Minneapolis, Minnesota

August 1995 


\section{Disclaimer}

This report was prepared as an account of work sponsored by an agency of the United States Government. Neither the United States Government nor any agency thereof, nor any of their employees, makes any warranty, express or implied, or assumes any legal liability or responsibility for the accuracy, completeness, or usefulness of any information, apparatus, product, or process disclosed, or represents that its use would not infringe privately owned rights. Reference herein to any specific commercial product, process, or service by trade name, trademark, manufacturer, or otherwise, does not necessarily constitute or imply its endorsement, recommendation, or favoring by the United States Government or any agency thereof. The views and opinions of authors expressed herein do not necessarily state or reflect those of the United States Government or any agency thereof. 
FERMILAB TM-1943, July 1995

SOME TESTS OF AVALANCHE PHOTODIODES
PRODUCED BY ADVANCED PHOTONIX, INC.

George W. Foster and Anatoly Ronzhin

Fermilab

Roger Rusack

Minnesota State University

\section{INTRODUCTION}

The goal of the measurements presented here is to check some parameters of the high gain avalanche photodiodes (APD's) produced by Advanced Photonix, Inc. [1]. Samples with $16 \mathrm{~mm}$ and $5 \mathrm{~mm}$ diameter sensitive areas were tested.

\section{SETUPS}

The tests were performed at FNAL. The new photomultiplier testing facility were used for gain measurements, linearity, and nonuniformity studies. The setup consists of laser with shifted wavelength of $440 \mathrm{~nm}, 10 \mathrm{~Hz}$ repetition rate and a pulse duration of $15 \mathrm{nsec}$. The laser light was transported to the APD by $1 \mathrm{~mm}$ diameter clear fiber. An amount of laser light was adjusted by rotating wheels of fixed light attenuation. The dynamic range of the APD, an amplifier (AMP) and an ADC was about 1000. To get the nonuniformity data the APD was mounted on a movable stage under management and control of computer. The positioning of the fiber along sensitive surface of the APD was better than 100 microns. The setup is shown in fig.1. 
A second setup was used to measure the APD signal for muons passing through the APD, and also for muons passing through a scintillator viewed by the APD. The scintillator size are $33 \times 17 \times 7$ $\mathrm{mm}$, and the side $7 \times 17 \mathrm{~mm}$ was viewed by the APD (fig. 2). The APD (with and without scintillator) was triggered by 2 scintillator counters.

The FNAL proton pool area magnet facility (fig. 3) was used to check APD's properties in magnetic field. It was possible to get there the magnetic field up to 2.43 Tesla. The nonuniformity of magnetic field along the APD's sensitive area was less than $3 \%$. A blue light pulse generator outside the magnetic field was used to illuminate the APD. The generator's blue light was transported to the APD by a clear optical fiber.

\section{MEASUREMENTS}

The supply voltage scheme for the APD recommended by producer was chosen (fig. 4). The gain of the of the APD as a function of bias voltage is shown in fig.5a. The uniformity of response is shown in fig. $5 \mathrm{~b}$.

Fig. 6 presents the linearity. The APD was tested for dynamic range 1000 . The noticed nonlinearity was less than $+0.35 \%$ and can be explained as an apparatus effect but not the APD itself. $90 \%$ of the charge is collected in $60 \mathrm{nsec}$.

Measurements of the APD output signal for muons passing through the APD as well as through the scintillator (through $7 \mathrm{~mm}$ of thickness) were performed for different gains (fig.7). The amount of photoelectrons produced by muons passing through the scintillator and the number of electrons produced by the muons ionization inside the APD also as their ratio in dependence on the gain are presented at the same picture. These values were estimated from knowledge of collected charge for all circuits used(APD gain, amplifier, ADC count etc.) in number of electrons. The signal produced by the scintillator, and also as by 30 layers of tile/fiber calorimeter (each layer giving 15 photoelectrons with the APD) is also shown in fig.8.

The data for the $5 \mathrm{~mm}$ diameter sensitive area APD are presented in fig.9, 10.

The APD were placed in magnetic field of 2.37 Tesla (fig.11). The gain of the APD's with and without magnetic field was tested first. No changes in the dependencies gain versus the bias was 
observed with better than $1 \%$ of accuracy (fig.12). The same was obtained for dependencies of the gain versus the magnitude of the magnetic field also as for the angle between the direction of the magnetic field and the electric field of the APD.

\section{ACKNOWLEDGMENTS}

We would like to thank Aesook Byon-Wagner, Julius Lentz and Hogan Nguyen for technical support. We appreciate Dan Green, Jim Freeman and John Elias for useful discussions. Our thanks to Marek Szawlowsky for the APD,s. 


\section{BIBLIOGRAPHY}

1.The Avalanche Photodiode Catalog, Advanced Photonix, Inc.,

1240 Avenida Acaso, Camarillo, CA 93012 


\section{FIGURES.}

1. Setup to measure gain, linearity and nonuniformity of the APD. APD - avalanche photodiode, AMP - amplifier, PIN - photodiode, WLS - wave length shifter, AW - attenuation wheel.

2. Setups to measure response of the APD to muons passing through the scintillator fastened to the APD as well as to muons passing through the APD. S1, S2 are triggering counters, Ru106 is a radioactive source.

3. Setup to study performance of the APD in the magnetic field.

4. APD's circuit diagram.

5. a) Dependence of the APD gain on bias voltage.

b) APD's nonuniformity (relative units) for two perpendicular directions.

6a. 1) APD linearity (APD signal versus PIN diode signal),

2) Deviation of APD signal from linear fit (ADC counts).

3) Deviation of APD signal from linear fit (percentage).

4) APD's resolution (sigma/mean for APD's signal's distribution) as a function of an illumination for different biases.

$5,6)$ Oscilloscope traces of the APD signals.

6b. The same as fig. 6a for lower values of the APD's gain and by using an amplifier on the output of the APD.

7. Distribution of: 1) signals of muons passing through scintillator, and 2) signals of muons passing through the APD for different bias voltage.

Two pictures in the lower right corner present the number of electrons dependent on the APD's gain of muons passing through scintillator, through the APD, and the ratio of these two values as function of gain.

8. Distribution of signals of the APD: a) for muons passing through scintillator, b) of muons passing through 30 tile/fiber layers, c) for pedestals.

9. The same as fig. 5 for $5 \mathrm{~mm}$ diameter sensitive area APD.

10 a,b. The same as figs. $6 \mathrm{a}, \mathrm{b}$ for $5 \mathrm{~mm}$ diameter sensitive area APD.

11. Schematic view of the magnet poles. The magnitude of the magnetic field as a function of coil current for different pole sizes.

12. The dependence of the APD $(5 \mathrm{~mm})$ gain: 1) on the bias with and without 2.37 Tesla magnetic field. Magnetic field is perpendicular to the APD's electric field. 2) on the angle between electric and 1 Tesla magnetic field. 3 ) on the magnitude of perpendicular magnetic field for different bias voltage. 4) The gain of the APD $(16 \mathrm{~mm})$ versus the magnitude of the magnetic field perpendicular to the electric field of the APD. 


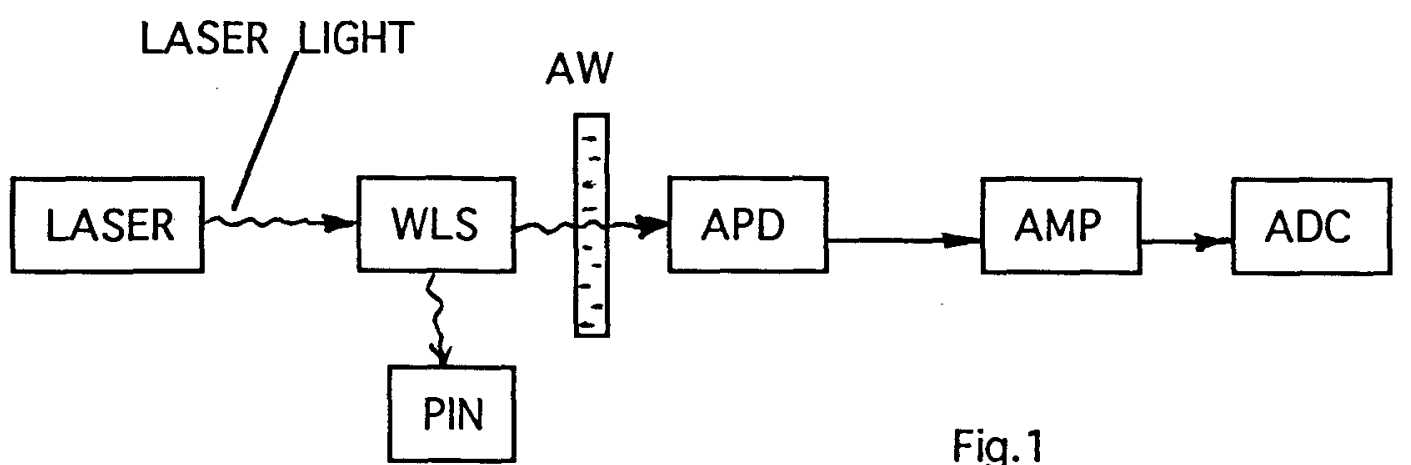

Fig. 1

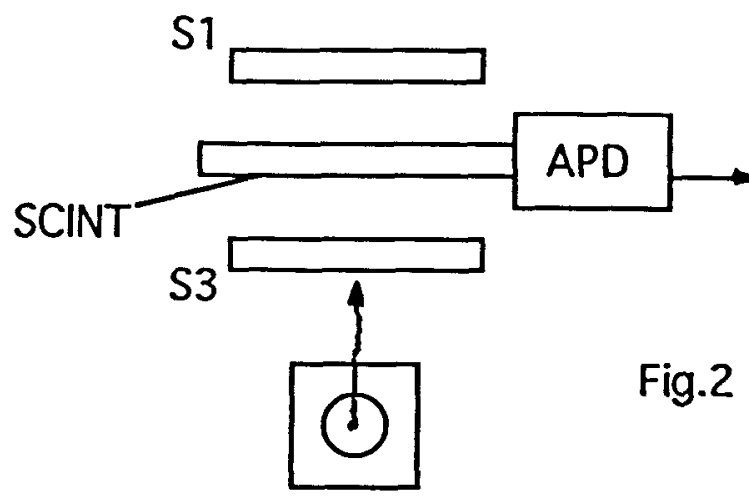

Ru 106

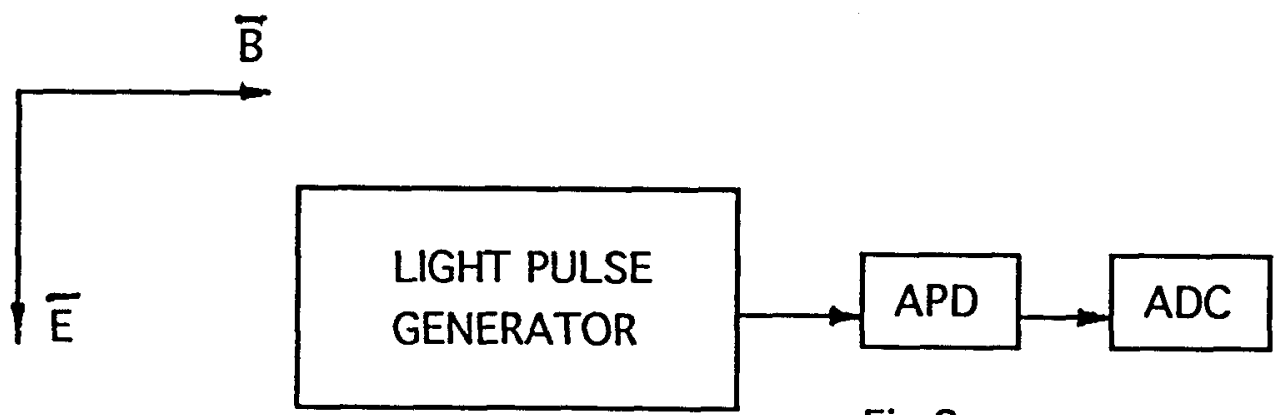

Fig. 3

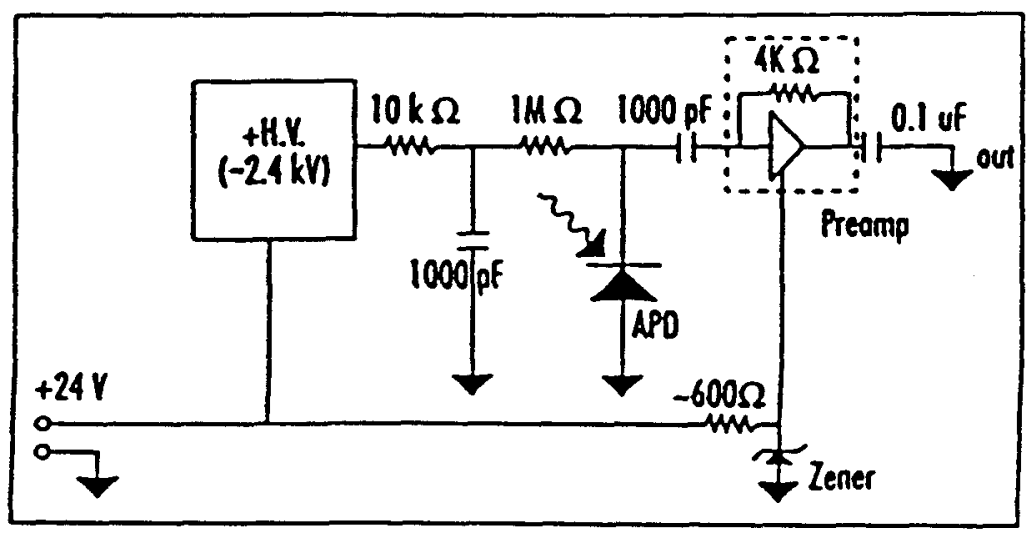

Fig.4 

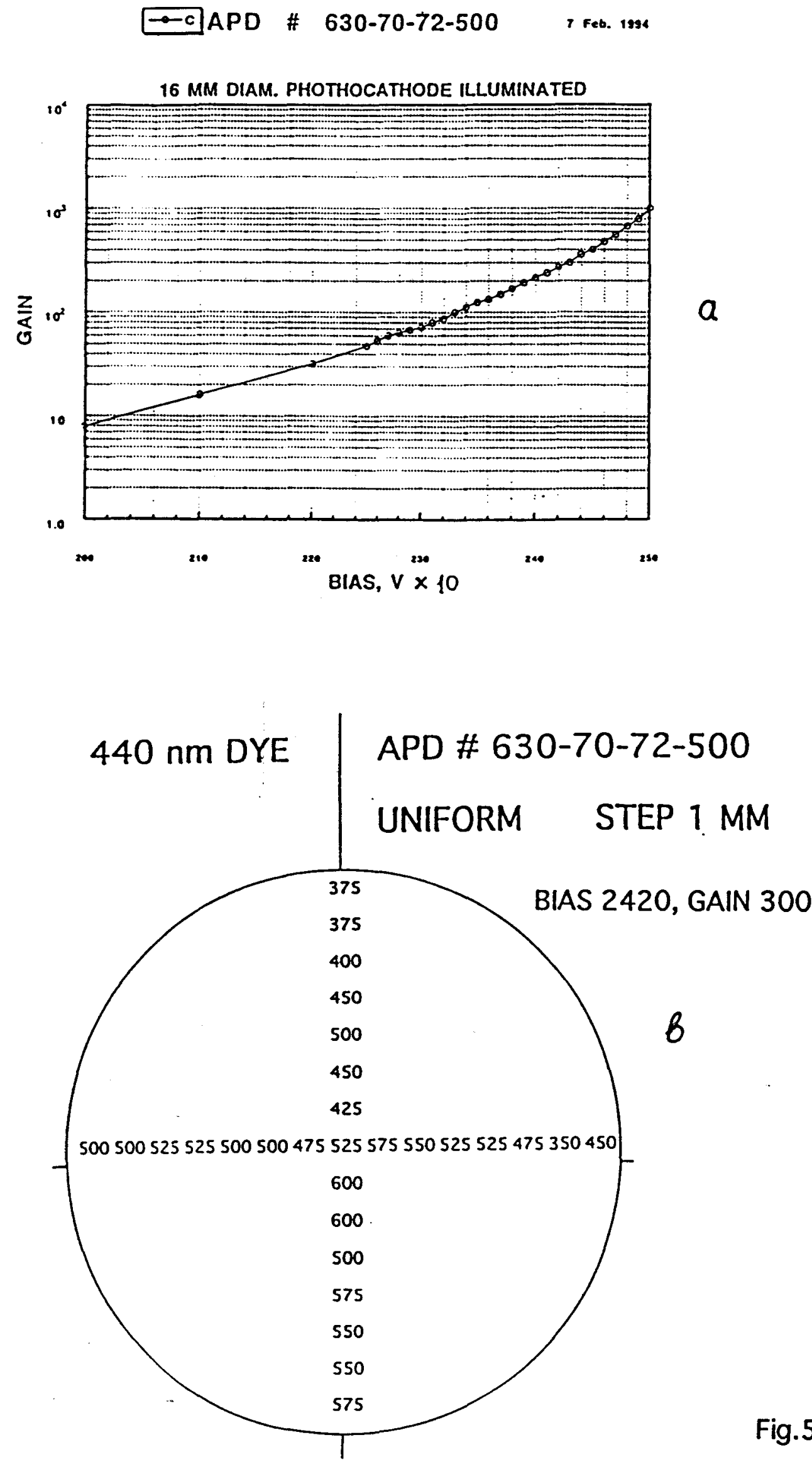
BIAS 2454, GAIN 450
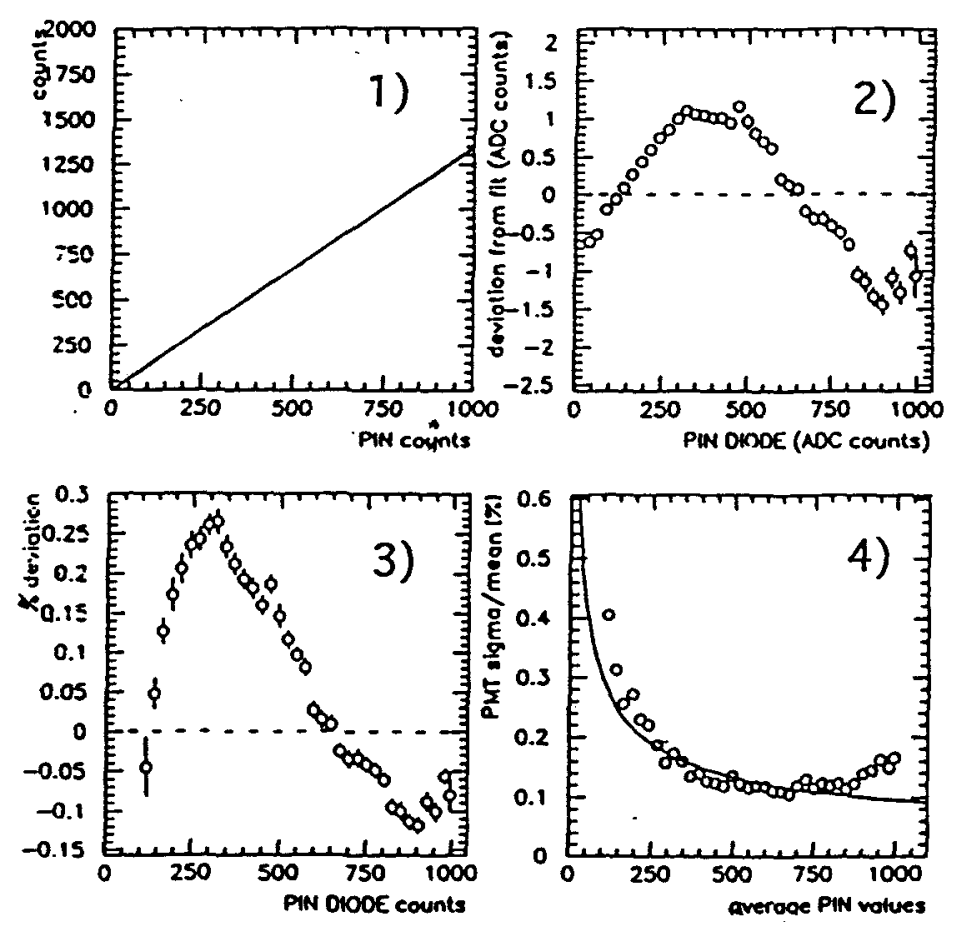

BIAS 2380, GAIN 170

$11 / 02 / 94 \quad 14.59$
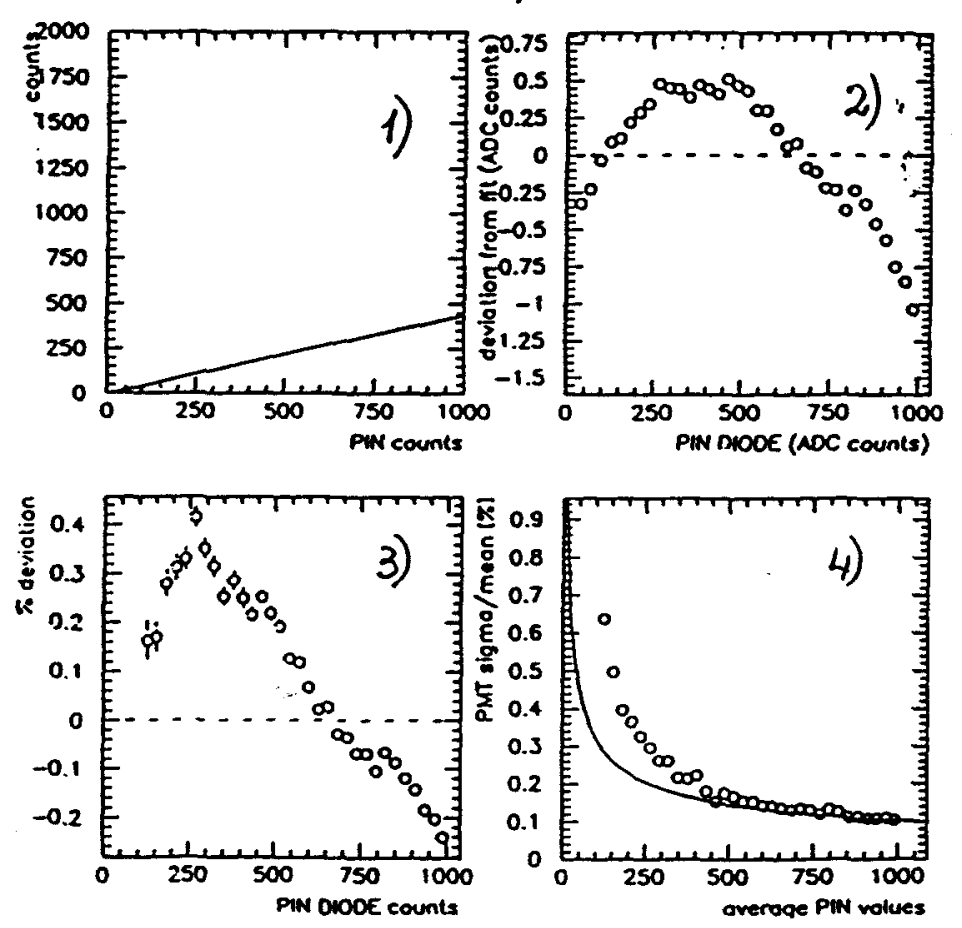

BIAS 2415, GAIN 250

$11 / 02 / 94 \quad 14.47$
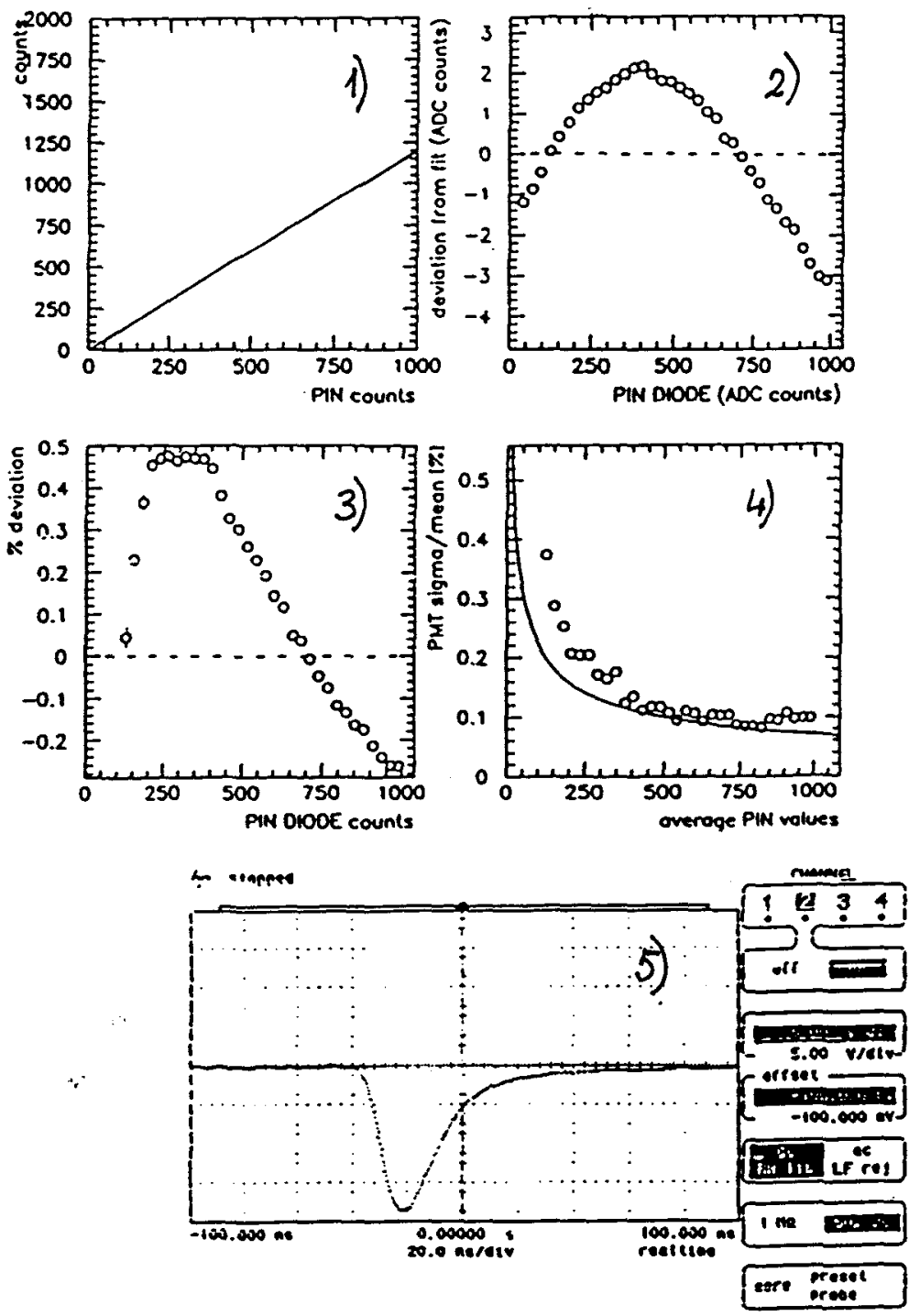

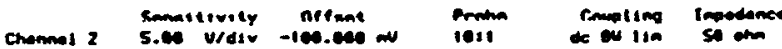

Trtoom model Edoe

on tho Poottive Edop of Chamelz

Trioger Levelfe!

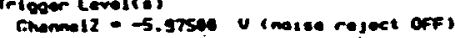

Moldope - a.een ne

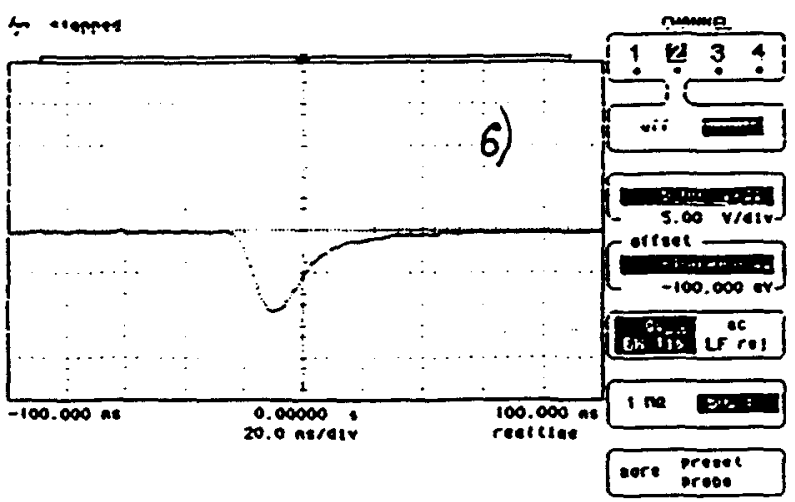

Fig.6a

Chemel 2 Senaltivity offiet of Probe coupling Inoedence

Trioger Hodes Edos

On the fostlive Edoe of Chamel2

Trioger Levells'

Holdople - ce.ces ns 
BIAS 2100, GAIN 15
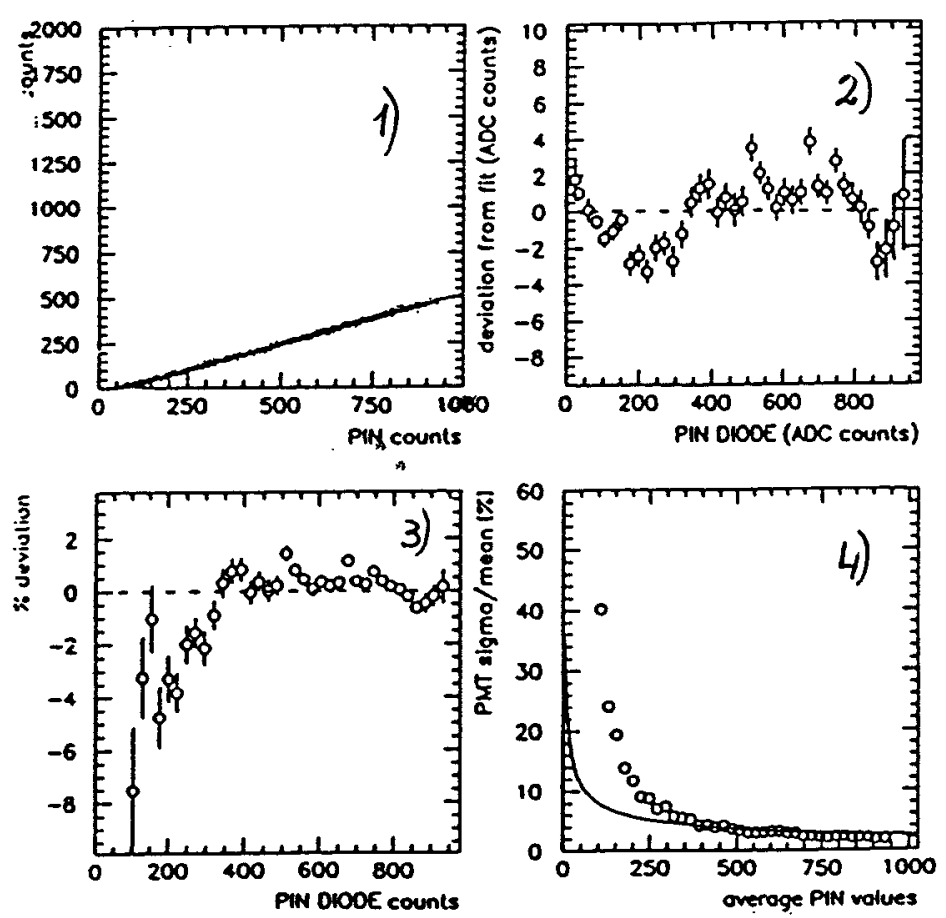

$11 / 02 / 94$

17.27
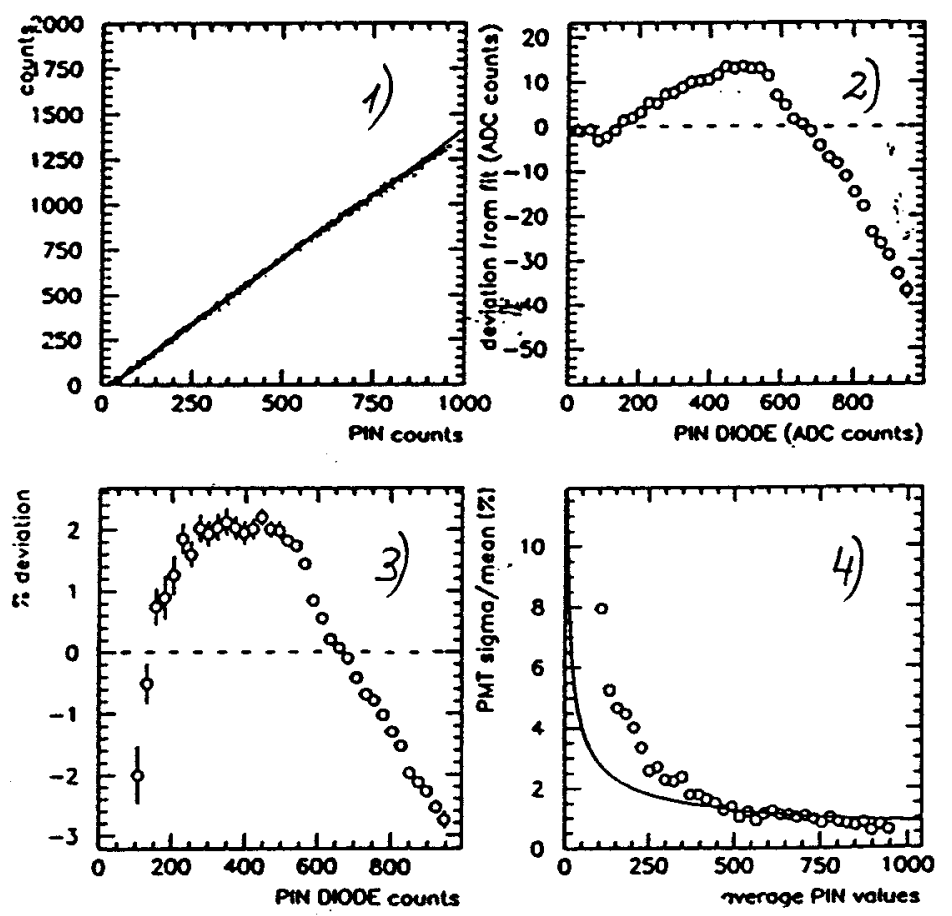
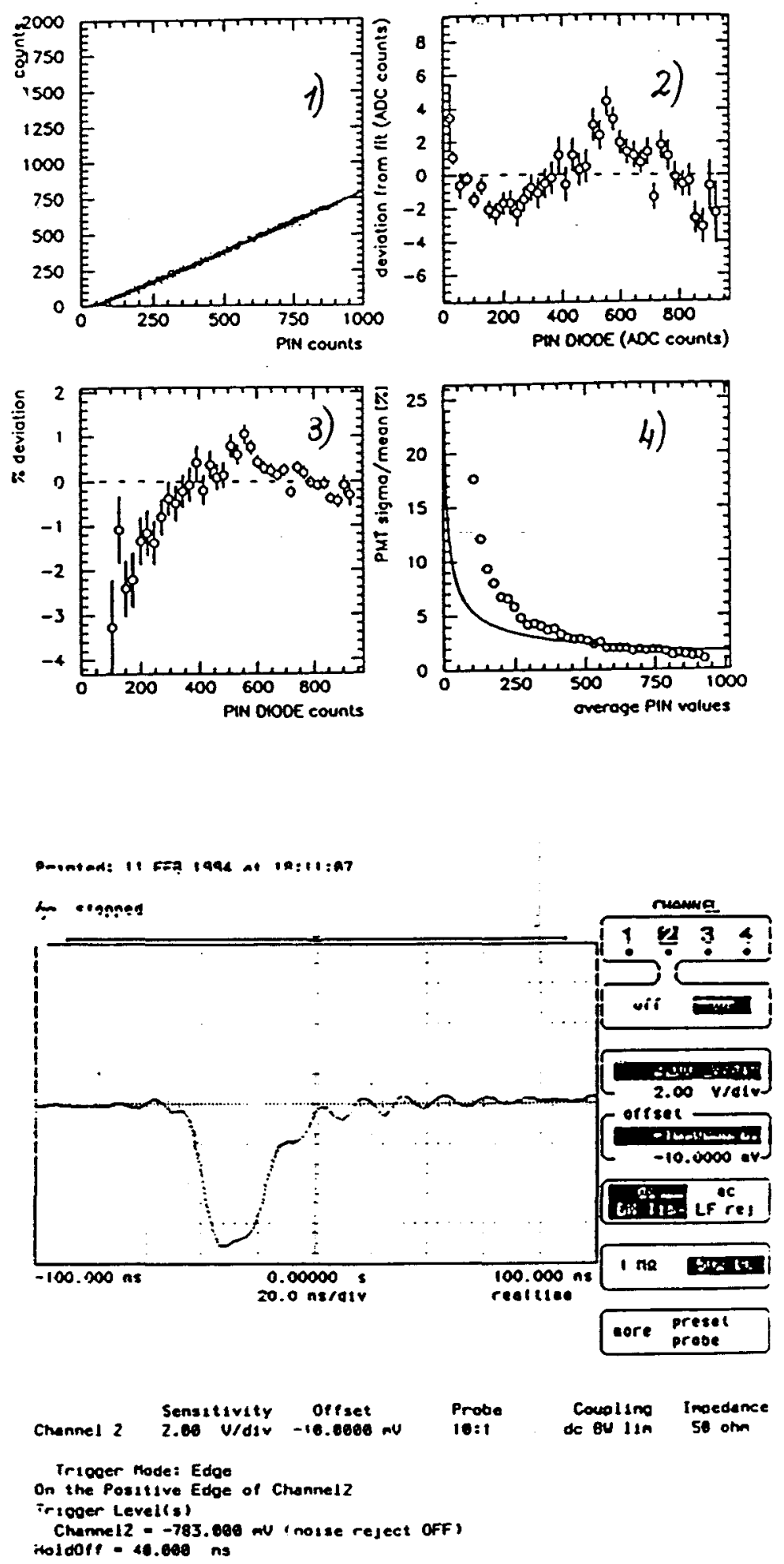

Fig. $6 b$ 
APD \# $630-70-72-50$
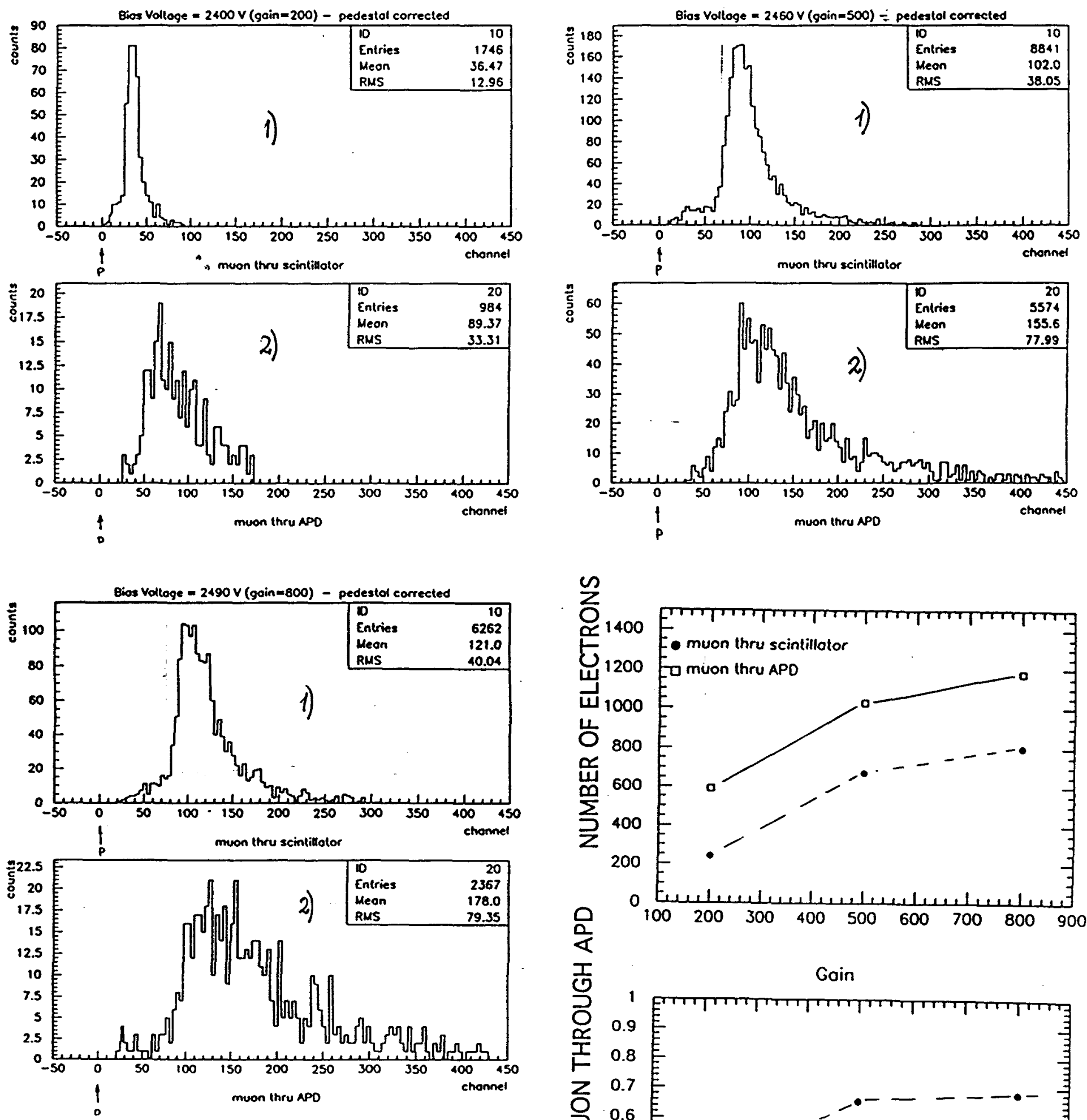

I

Gain

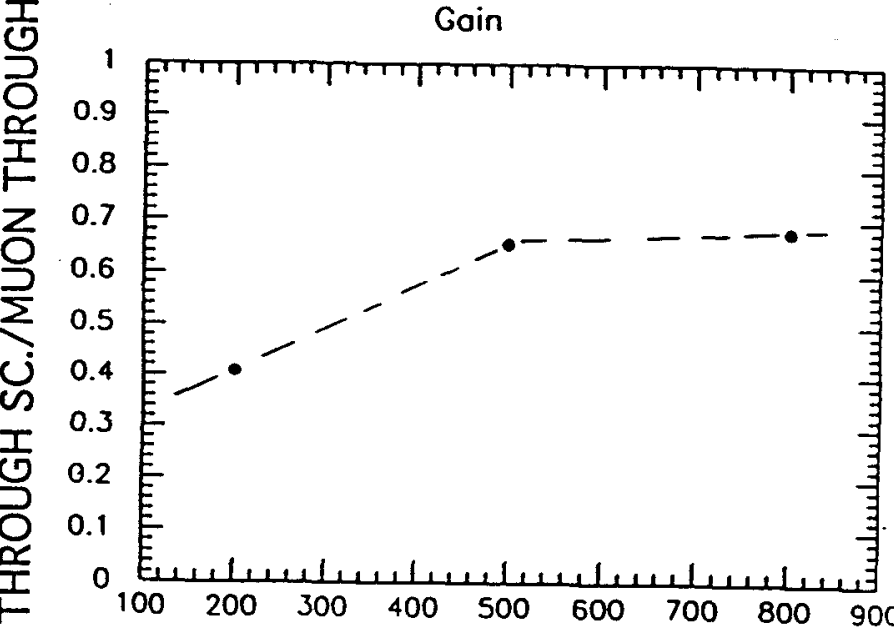

Gain 

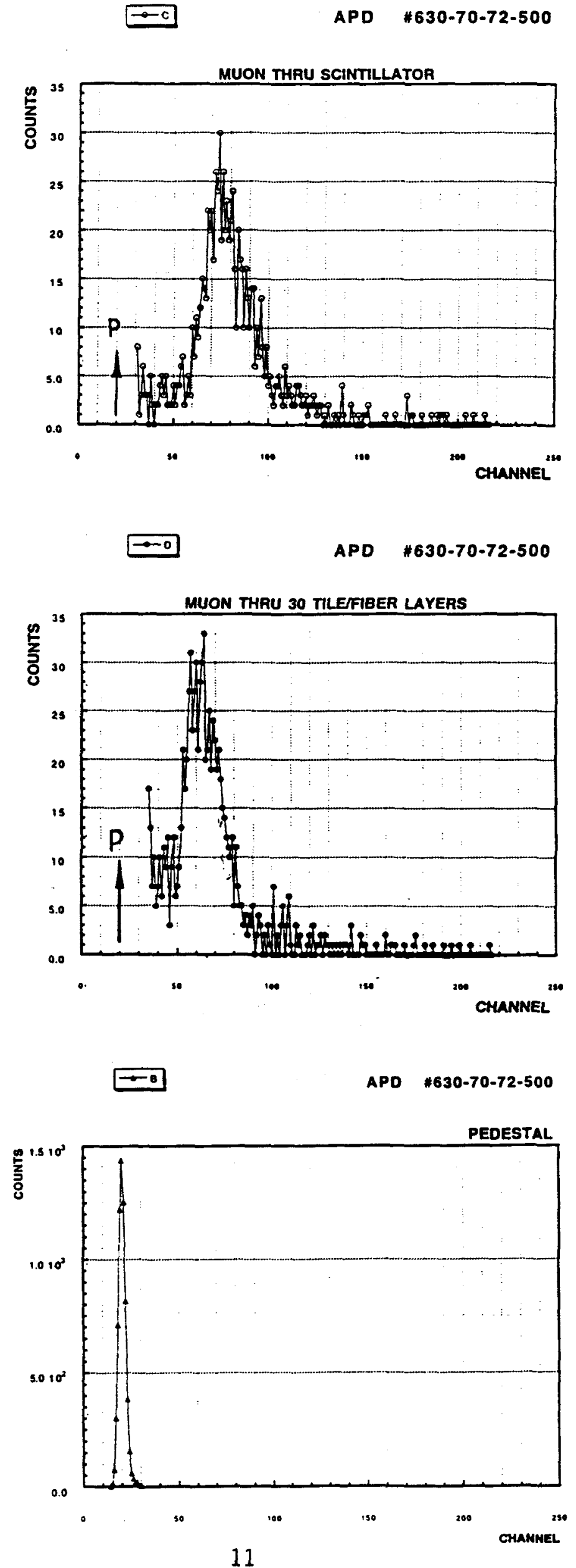

Fig. 8 


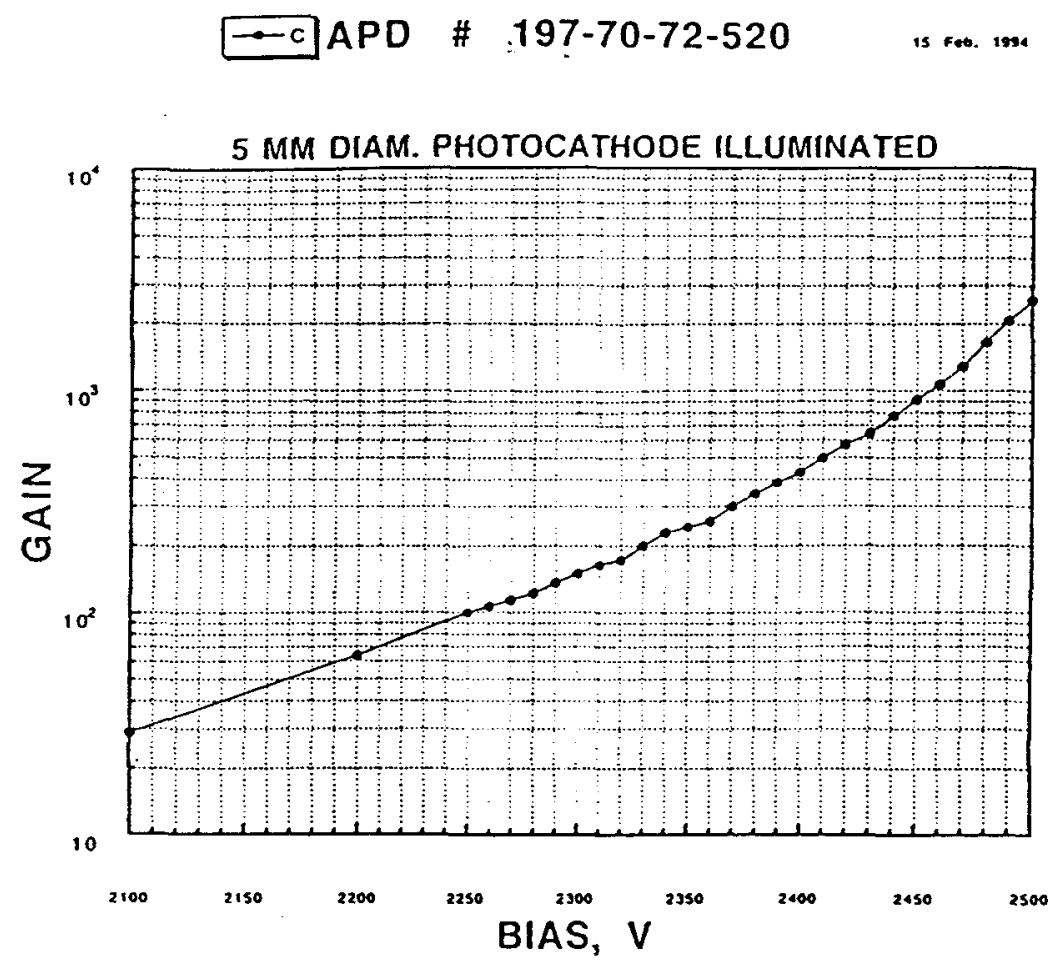

\section{0 nm DYE $\quad$ APD \# 197-70-72-520}

UNIFORM. STEP $1 \mathrm{MM}$

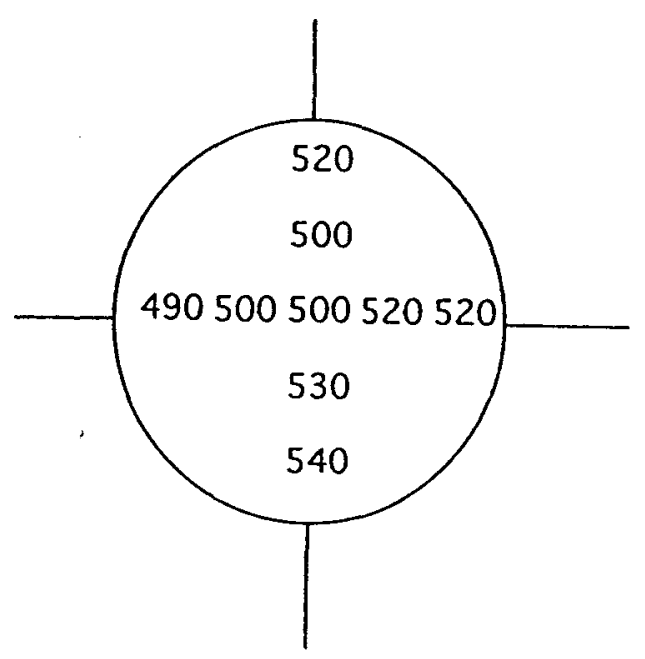

Fig.9 
BIAS 2430, GAIN 630
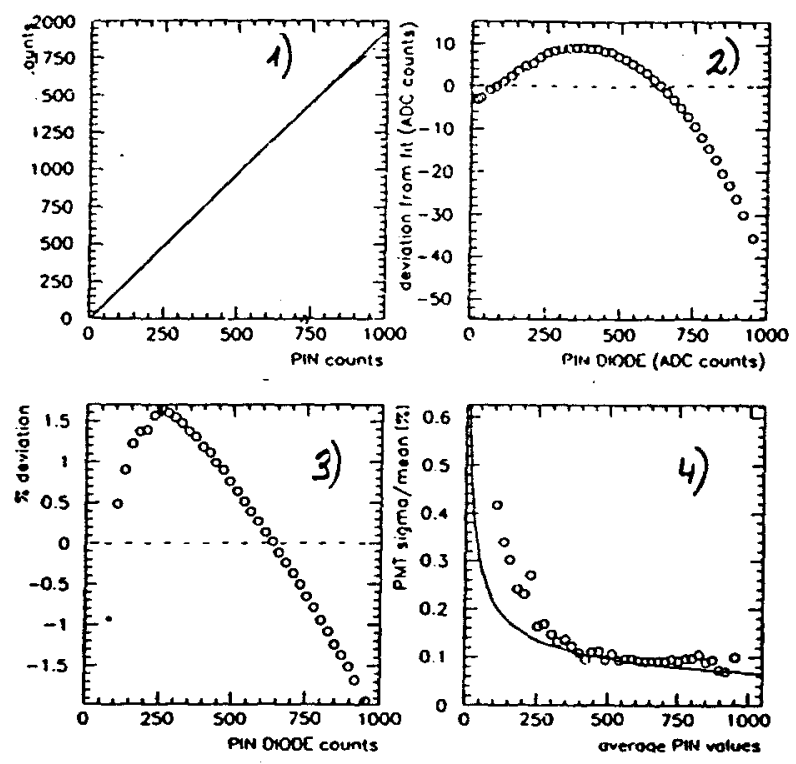

$11 / 02 / 94 \quad 22.04$
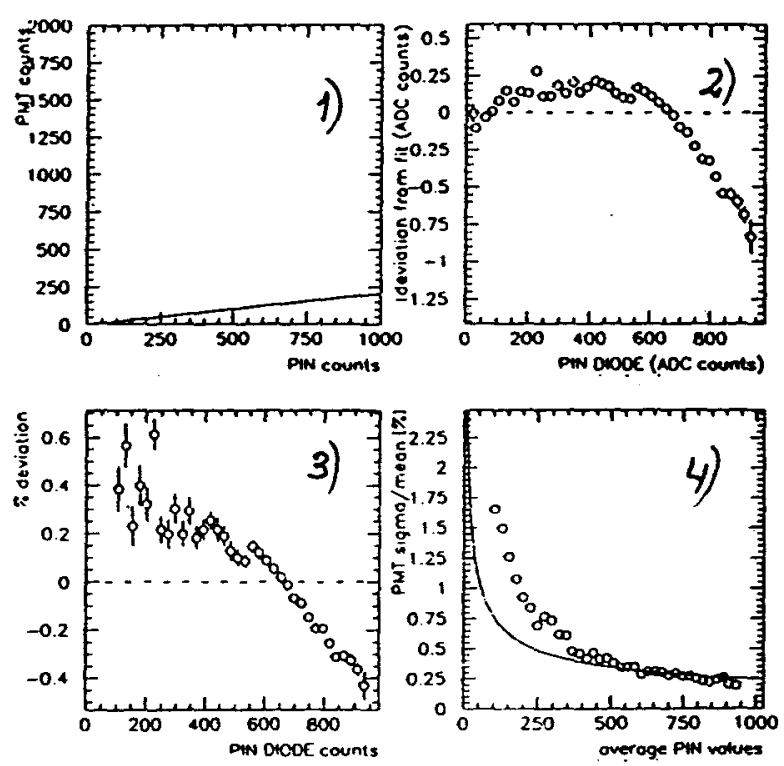
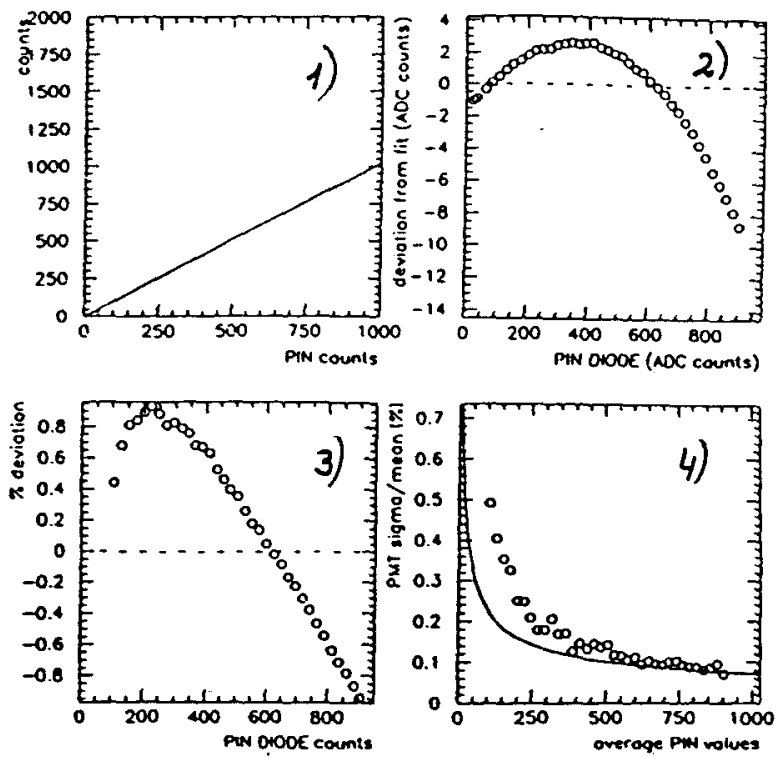

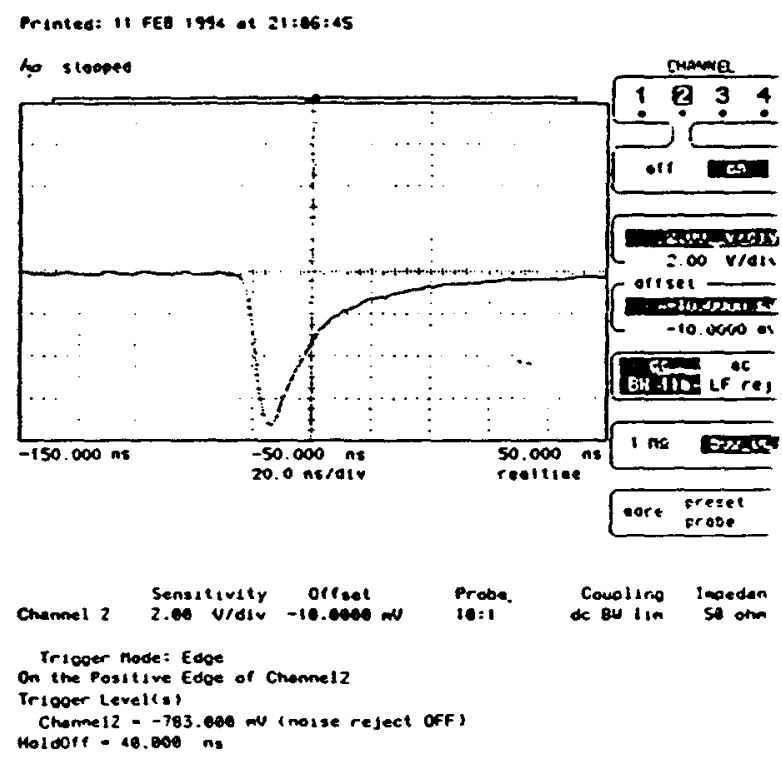

Fig.10a 
BIAS 2467, GAIN 1200 11/02/4s 20.59
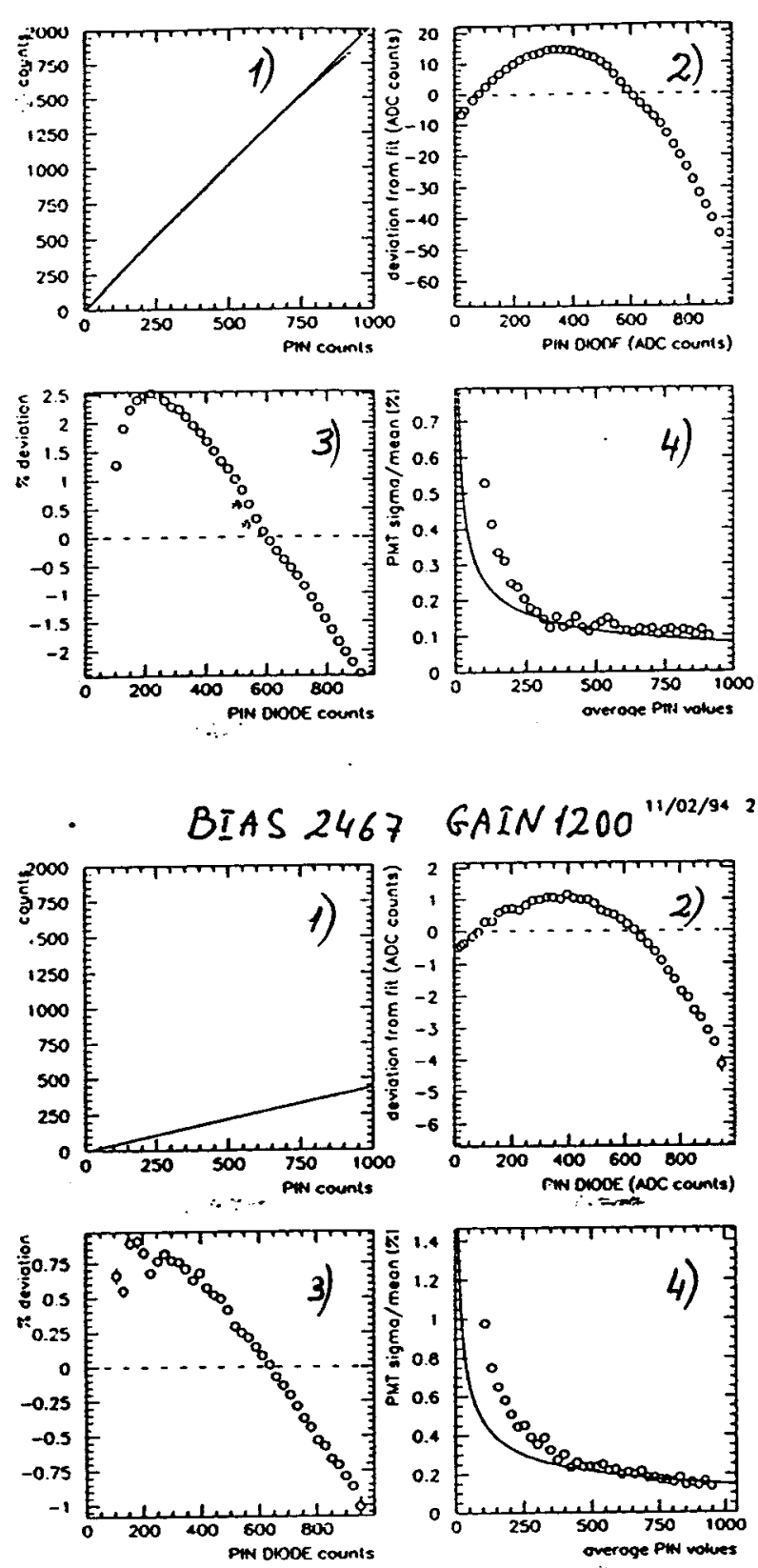

BIAS 2500, GAIN $2600::_{00}^{11 / 02 / 942148}$
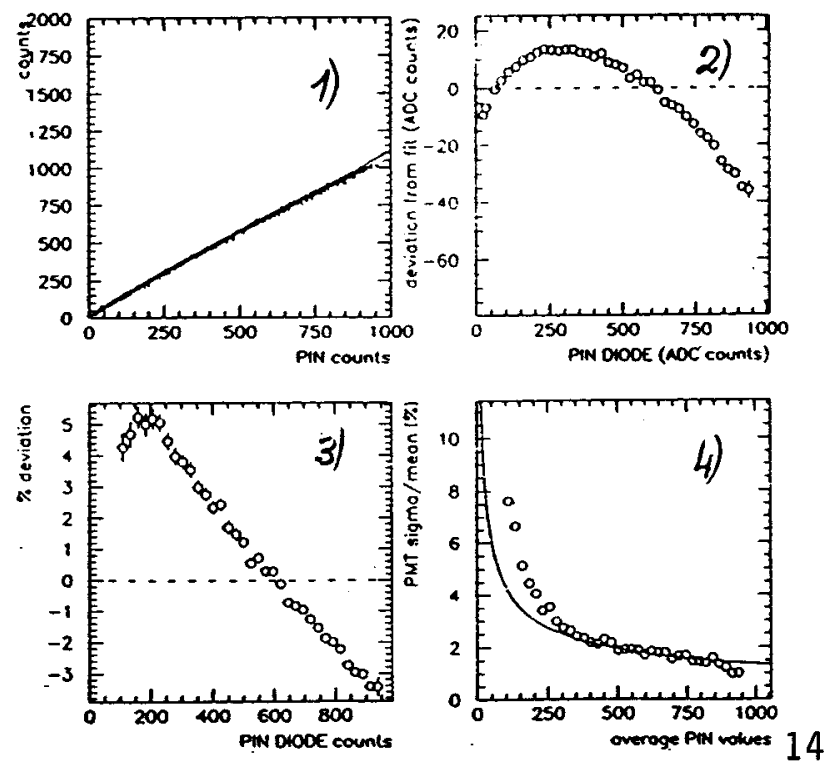

BIAS 2467, GAIN 1200

$11 / 02 / 9421.11$
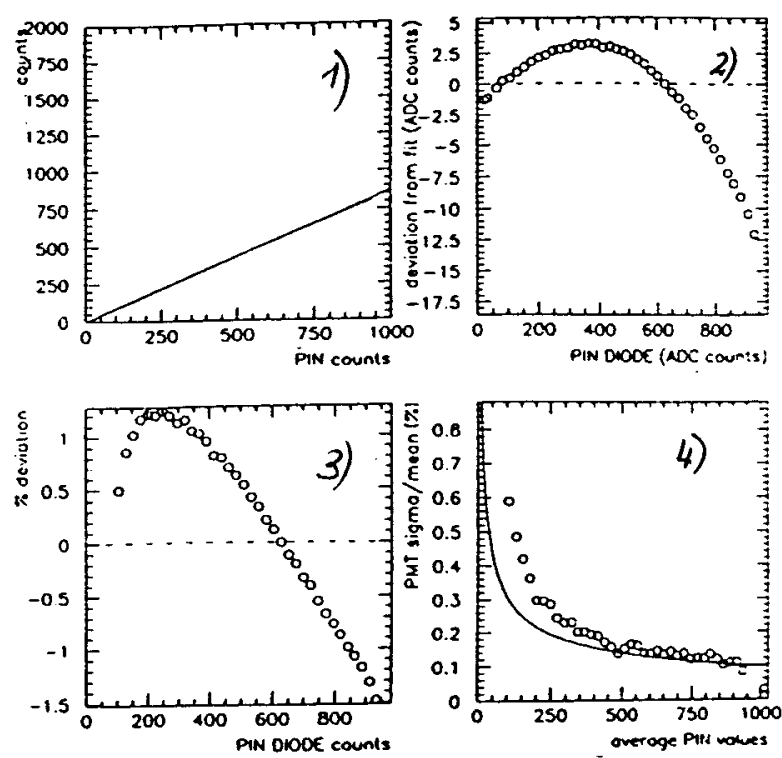

Fig. 10b

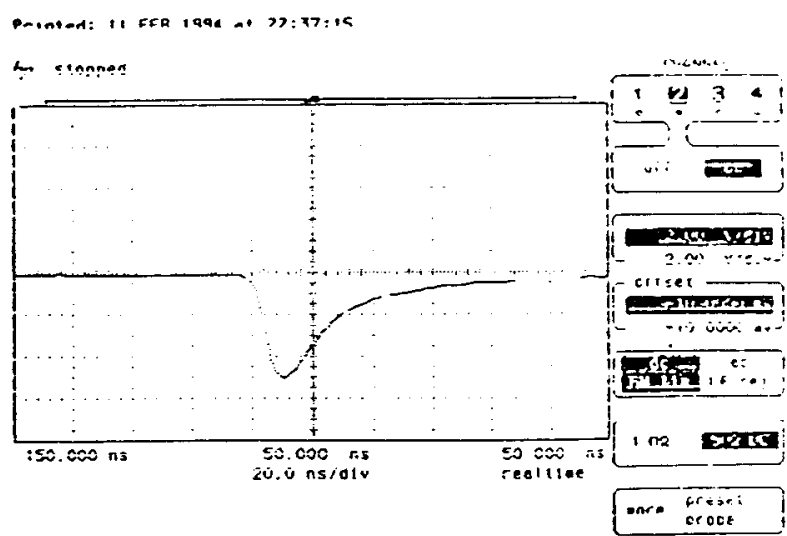

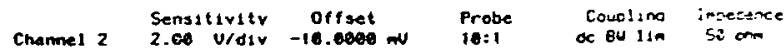

Triocer Mode: Edoe

On the Positive Edoe of Chemel2

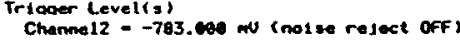

Holooff = $40.600 \mathrm{mos}$ 

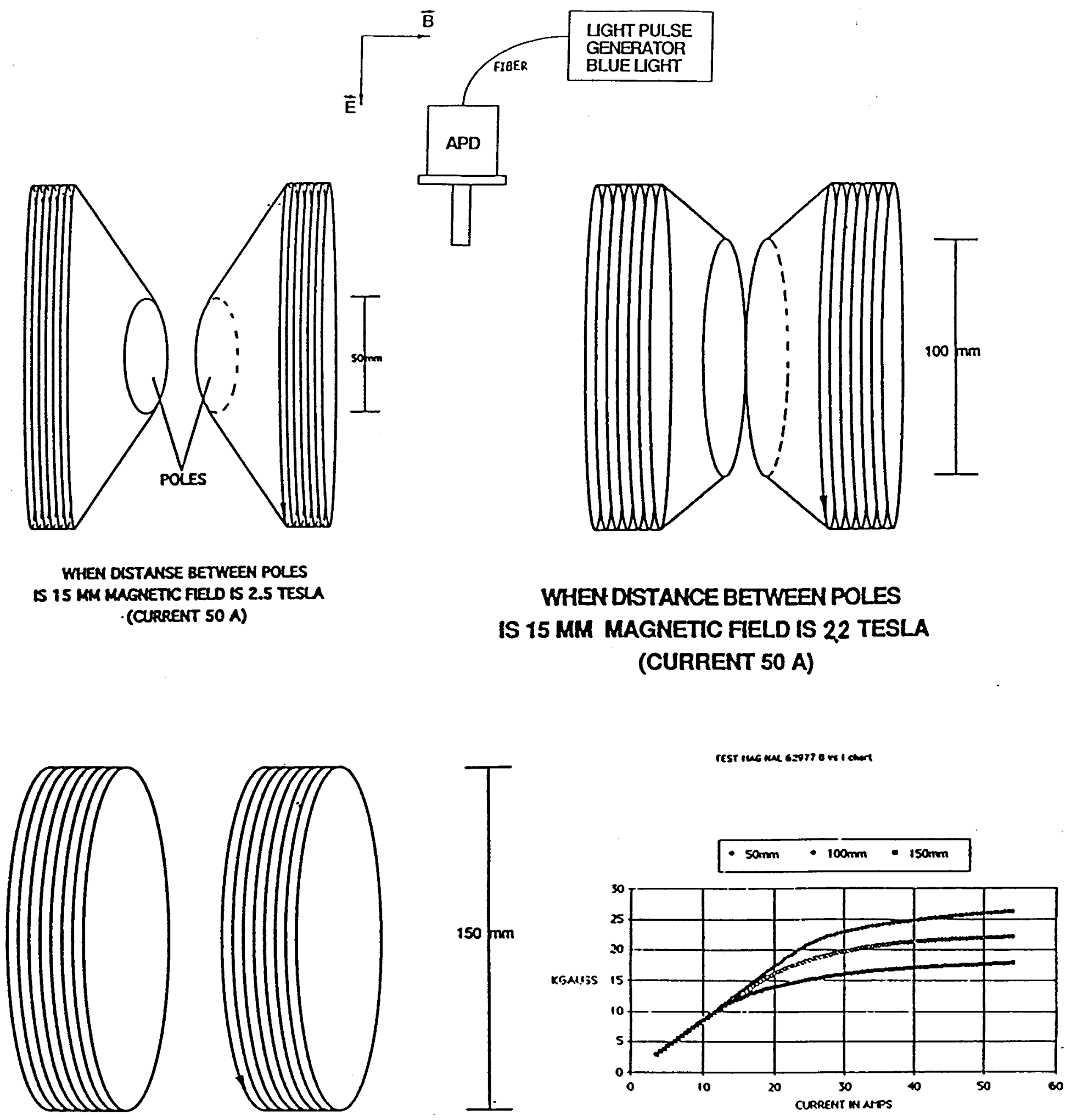

MAGNETIC FIELD ISLT TESLA 15 MM DISTANCE BETWEEN POLES

Fig.11 

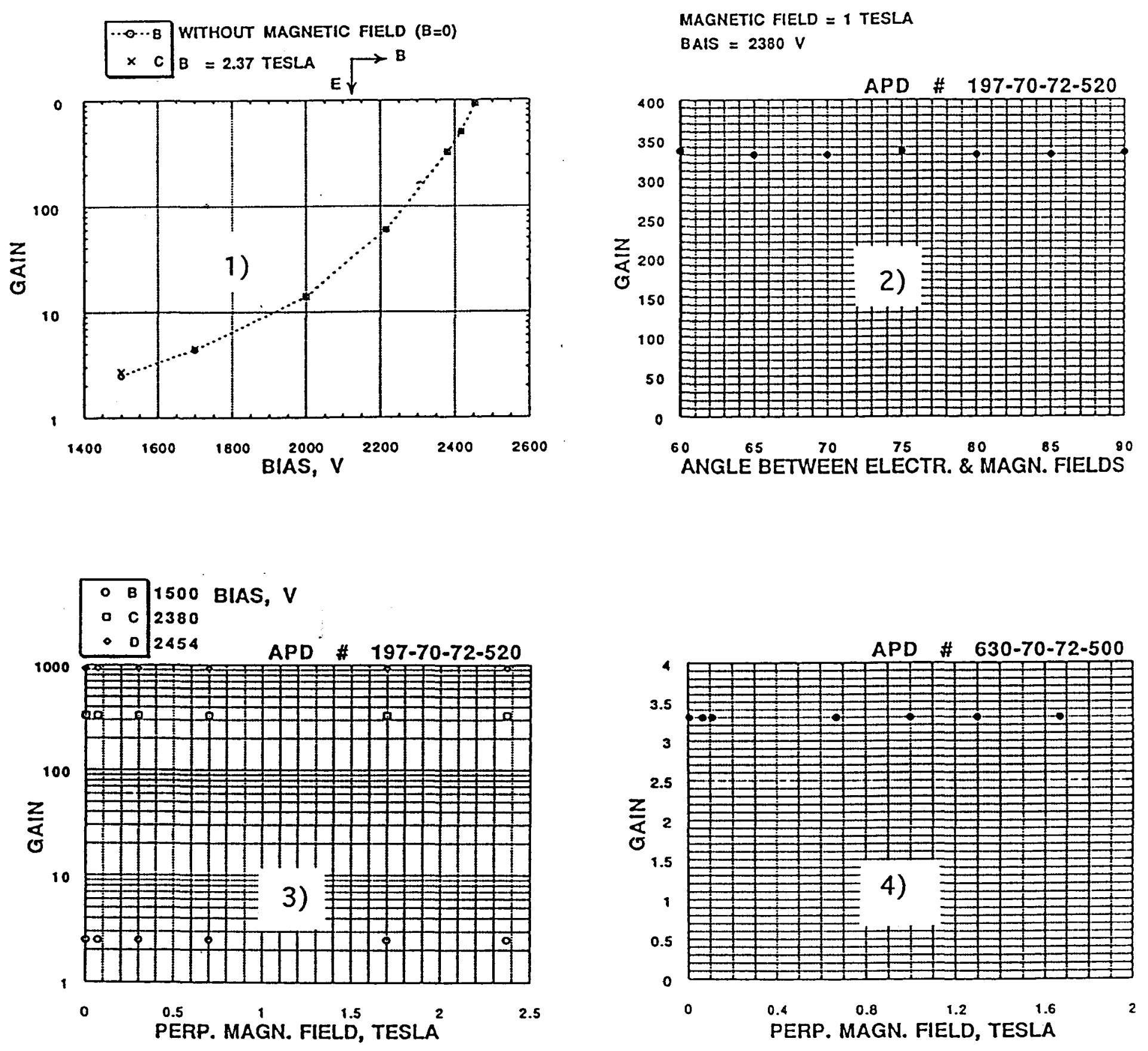

Fig. 12 